\title{
Mulemba
}

Revista Angolana de Ciências Sociais

6 (11) | 2016

Políticas, direitos e práticas da sociedade e do Estado

\section{A investigação científica na África contemporânea}

\section{Pedro Patacho}

\section{OpenEdition}

\section{Journals}

\section{Edição electrónica}

URL: http://journals.openedition.org/mulemba/1671

DOI: 10.4000/mulemba.1671

ISSN: 2520-0305

\section{Editora}

Edições Pedago

\section{Edição impressa}

Data de publição: 1 maio 2016

Paginação: 333-340

ISSN: 2182-6471

\section{Refêrencia eletrónica}

Pedro Patacho, «A investigação científica na África contemporânea», Mulemba [Online], 6 (11) | 2016,

posto online no dia 13 outubro 2018, consultado o 26 janeiro 2021. URL: http://

journals.openedition.org/mulemba/1671 ; DOI: https://doi.org/10.4000/mulemba.1671 


\title{
A investigação científica na África contemporânea*
}

\author{
Pedro Patacho**
}

Permitam-me em primeiro lugar que agradeça o amável convite do Senhor Decano da Faculdade de Ciências Sociais da Universidade Agostinho Neto, Professor Doutor Víctor Kajibanga, para realizar a apresentação dos Livros I, II e III, que o insigne intelectual camaronês Jean-Marc Ela dedicou à temática da investigação científica na África contemporânea. Trata-se da tradução dos originais em francês, publicados pelas Éditions L'Harmattan em 2007.

Irei abster-me aqui de reproduzir as violentas críticas que o autor formula ao longo do seu livro a vários países africanos, particularmente aos seus governos, às suas universidades e às suas elites.

* Texto de apresentação pública da tradução portuguesa de três (3) obras de Jean-Marc Ela: Investigação científica e crise da racionalidade - Livro I (Tradução de Narrativa Traçada, revisão de Susana Ramos. Luanda, Edições Mulemba; Ramada, Edições Pedago, 2015, 112p. [ «Reler África»]); As culturas africanas no âmbito da racionalidade científica - Livro II (Tradução de Sílvia Neto, revisão de Susana Ramos. Luanda, Edições Mulemba; Ramada, Edições Pedago, 2016, 152p. [«Reler África»]); A investigação africana face ao desafio da excelência científica - Livro III (Luanda, Edições Mulemba; Ramada, Edições Pedago, 2016, 148p. [«Reler África»]), que teve lugar o Anfiteatro principal da Faculdade de Ciências Sociais (FCS) da Universidade Agostinho Neto (UAN), no dia 28 de Março de 2016, no âmbito das suas actividades académicas pela abertura do Ano Lectivo de 2016.

** Investigador do CEREPE - Centro de Recursos Pedagógicos da FCS-UAN (Angola); Professor Adjunto do Instituto Superior de Ciências Educativas e Investigador do CI-ISCE - Centro de Investigação do Instituto Superior de Ciências Educativas (Portugal) e do Departamento de Pedagoxía e Didáctica da Universidad da Coruña (Reino da Espanha); Director das Edições Pedago. 
Tratarei sim de sintetizar as grandes linhas de força que resumem os argumentos do autor, mas convidando-vos desde já a deixarem-se invadir pelo poder das suas palavras, potencialmente transformadoras das vossas concepções e práticas enquanto estudantes, professores ou investigadores africanos.

O Livro I, intitulado Investigação científica e crise de racionalidade, começa por colocar uma questão pertinente: O que é a ciência? Para o autor, trata-se de um empreendimento humano historicamente situado, social e culturalmente fundado nos sujeitos investigadores, que nunca são sujeitos neutros. Deste ponto de vista, definir a cientificidade - os critérios a partir dos quais se julga a admissão dos saberes na galeria dos conhecimentos científicos - «pressupõe sempre a existência de um paradigma» (Livro I, 2015: 15).

Como nos lembram Egon Guba e Yvonna Lincoln (1994), os paradigmas constituem assunções básicas que representam diferentes visões do mundo e que definem a própria realidade, ainda que não possa ser estabelecida definitivamente a sua veracidade. Contudo, a assunção de um determinado paradigma atira «para fora do escopo da ciência» aquilo que não se tornou aceite entre os cientistas que defendem esse paradigma, ou seja, dito de outro modo, a defesa de um determinado sistema de saberes (uma ciência) é ao mesmo tempo a negação de outros sistemas de saberes. Isto legitima desde logo a questão: Contra quê e contra quem se construiu e constrói a ciência moderna?

Para responder a esta questão desafiadora Jean-Marc Ela localiza o conceito de ciência na tradição histórica à qual este se amarra. Ao fazê-lo, para compreender como a razão «passou da filosofia e da política para a ciência» (Livro I, 2015: 16), reconhece o domínio das abordagens que apresentaram e continuam a apresentar a história da razão através da Antiguidade Grega. Neste percurso, segundo o autor, "povos inteiros, designadamente da África negra»(Idem), foram ignorados, como se a sua existência correspondesse a uma espécie de pré-história da razão. A conclusão do intelectual camaronês é, pois, óbvia: «não é garantido que a ideia de ciência não seja efectivamente abrangida pelo etnocentrismo» (Idem).

Como tal, considera o autor, «há uma crise de racionalidade na ideia que se concebe da razão e da ciência. Esta crise esconde-se no âmago da razão ocidental, que, ao fechar-se sobre si mesma, se consagra como [a] razão universal» (Livro I, 2015: 18), que mais não é, afinal, do que «um modelo racionalizador dominante que oculta 
outras formas de racionalidade» (Idem), assunto que será desenvolvido com maior detalhe no Livro II, As culturas africanas no âmbito da racionalidade científica.

Jean-Marc Ela salienta inúmeros exemplos que provam sem margem para dúvidas que a humanidade não esperou pelo Ocidente para fazer ciência. A profusão de estudos que são citados neste livro sobre a produção do saber na Antiguidade e as ligações de outras civilizações aos povos europeus deixam claro o quão absurdo é localizar o nascimento da razão na Antiguidade grega. Algo que, de resto, há muito que Cheikh Anta Diop demostrou (ELA 2014).

No entanto, também mostra como a civilização ocidental conseguiu impor a ideia de uma suposta universalidade da sua razão, o que mais de assemelha a uma «camuflagem ideológica de uma visão limitada e parcial do mundo e de uma prática conquistadora, destruidora das culturas não-ocidentais» (Idem). O sucesso desta imposição surge estreitamente associado a uma série de mitos (entre os quais o mito fundador da ciência moderna personificado na figura de Galileu Galilei e na sua luta pela liberdade de pensamento), que opõem o obscurantismo religioso à razão científica, a vida quotidiana à prática da ciência, todas as formas de conhecimento ao «verdadeiro» método para chegar ao conhecimento de todas as coisas.

É este modelo de racionalidade que se vai impor como supostamente universal porque assente na validação matemática mediante procedimentos de demonstração. Com efeito, as mãos pesadas do quantitativo e da demonstração matemática silenciarão durante muito tempo outros saberes e outras formas de produção de conhecimento que serão simplesmente desacreditadas, desprezadas e relegadas para as margens do conhecimento supostamente «legítimo».

$\mathrm{O}$ «imperialismo deste modelo, que tende a submeter toda a inteligibilidade à égide do quantitativo» (Livro I, 2015: 33), um modelo que se expandiu a todas as áreas do saber e que se consolidou ao longo de séculos, recusando outras formas de racionalidade, constitui o ponto central da crise de racionalidade que Jean-Marc Ela discute neste volume. A partir daqui o autor explica como esta crise fundamental se desdobra noutras que colocam verdadeiramente em causa a ciência moderna, tal como se foi construindo nos últimos séculos.

Por exemplo, o endeusamento da ciência como fonte das derradeiras respostas a todas as questões, quando dentro da própria ciência, no seu âmago, tudo está verdadeiramente em causa, uma vez que o conhecimento se produz com base em avanços e recuos, tentativa e 
erro. Ao mesmo tempo, o endeusamento dos cientistas e especialistas como sujeitos neutros no caminho incorruptível de uma busca desinteressada e objectiva da «verdade». Por sua vez, a apresentação da «verdade» científica como única e como a única explicação (construção) possível da realidade.

Estes, entre outros, são os «oráculos dos tempos modernos» ( $\mathrm{Li}$ vro I, 2015: 32), os dogmas da nova «religião positivista» (Livro I, 2015: 38), que não apenas se apresenta com tiques imperialistas face a outras formas de racionalidade, como induz a construção de um imaginário público sobre a ciência e os cientistas muito distante da verdadeira natureza da ciência e da prática científica. Este imaginário convida a um certo exotismo da experiência e da cultura científica que, na perspectiva do autor, urge desmascarar.

Para tal é necessário compreender que no âmbito da relação saberpoder, a busca do saber compreende estratégias de poder. De modo que, como nos diz Ela, é necessário «desencriptar a banalidade» ( $\mathrm{Li}$ vro I, 2015: 52), para colocar «as tribos científicas a nú» (Livro I, 2015: 51), o que implica uma nova visão antropológica e sociológica da ciência e dos cientistas, no âmbito da qual os estudos do quotidiano da prática da ciência devem merecer um lugar de destaque, a fim de desfazer os mitos da ciência e abrir espaço para outras formas de racionalidade.

O caminho para superar a crise de racionalidade que Jean-Marc Ela discute com extrema erudição e profundidade, está na construção de uma outra ciência que aceite a complexidade do real, por um lado, e que dialogue com outras formas de racionalidade, por outro. Aqui encontramos o cerne do debate que vai estruturar os dois volumes seguintes, a saber, "a responsabilidade e o papel dos investigadores africanos na reinvenção da ciência» (Livro I, 2015: 104).

Sendo certo que não existe ciência, tal como não existe pensamento, fora da linguagem, da cultura e da sociedade, e sendo igualmente verdade, como frisou Mudimbe (2013), que não se trata exactamente de construir uma ciência inteiramente nova a partir da alteridade do investigador africano, há que compreender o papel da obra As culturas africanas no âmbito da racionalidade científica. Entramos assim no Livro II.

Compreender esse papel implica renunciar tanto aos mitos da ciência, tal como historicamente construída no universo sociocultural ocidental, como à imagem que essa mesma tradição intelectual construiu de África e dos africanos, recheada de mitos seculares que 
tornaram possíveis falsas «divisões entre os povos e as actividades humanas» (Livro II, 2016: 28). Algo que nem sempre os intelectuais africanos conseguem desconstruir.

É, pois, necessário recusar o mito da «excepção negra», da incapacidade dos povos africanos de produzirem um pensamento e uma prática no âmbito da ciência. Jean-Marc Ela sustenta que «não se deve hesitar em utilizar a palavra ciência» (Livro II, 2016: 47) para descrever os saberes que ao longo dos tempos foram produzidos nas sociedades africanas, uma vez que esses saberes resultam de algo que é comum a todas as sociedades humanas desde tempos imemoriais, isto é, a explicação, a previsão e o controlo dos fenómenos.

Assim, «deve evitar-se encerrar o pensamento africano no universo das crenças, levando a acreditar que a tradição africana comporta apenas as representações colectivas relativas às divindades e aos espíritos [...]» (Livro II, 2016: 48). O autor salienta inúmeros exemplos que o campo da etnociência tem evidenciado, aquilo a que podemos chamar de outra ciência, produzida nos espaços de racionalidade exteriores ao universo sociocultural ocidental, e que cobre uma ampla variedade de campos do saber. São provas irrefutáveis da capacidade de descoberta dos povos africanos ao longo da história para fazer face aos desafios do seu meio através dos conhecimentos substantivos e processuais por si desenvolvidos.

A questão que se coloca é então a seguinte: «Como reactualizar esta memória das origens nas sociedades actuais?» (Livro II, 2016: 61). A este propósito é preciso não confundir inteligência com instrução académica para conseguir discernir os saberes que emergem do património cultural endógeno dos povos africanos. A inclusão deste património na arena em que se confrontam os conhecimentos, designadamente no espaço académico e científico da universidade africana, cria as condições de possibilidade para um encontro de racionalidades de onde brote um contributo original dos cientistas africanos para a ciência mundial, que é, ao mesmo tempo, um contributo para a superação da sua crise de racionalidade.

Impõe-se, assim, a libertação da tirania do irracional, não para abraçar cegamente a tirania da racionalidade ocidental, «que não tolera outra verdade que não a sua» (Livro II, 2016: 71), mas para fazer penetrar no universo mundial da ciência o contributo original africano, resgatando a «honra de pensar», assumindo os riscos epistemológicos de pensar diferente que «põem à prova as novas sociedades africanas na aventura científica» (Livro II, 2016: 78). 
Um dos primeiros desafios que se coloca é, do ponto de vista de Jean-Marc Ela, a fraca percepção da ciência que predomina nas sociedades africanas contemporâneas. $\mathrm{O}$ autor procede a uma longa inventariação daqueles que identifica como graves problemas do ensino superior e da investigação científica em África, apresentando dados e exemplos de inúmeros países. Um outro desafio tem que ver com o uso das tecnologias da informação e do conhecimento, em particular a Internet, com o seu estendal de informação à distância de um clique. Sendo óbvias as suas enormes potencialidades para o desenvolvimento da ciência nas universidades africanas, é necessário considerar estas tecnologias como espaços de poder que «acentuam o processo de expansão dos conhecimentos do ocidente iniciado no século XIX» (Livro II, 2016: 111).

A este processo não são alheias as grandes agências e instituições internacionais que, se por um lado vincam a importância da ciência e do ensino superior para o desenvolvimento, por outro fazem-no num alinhamento perfeito com os seus próprios interesses e projectos. É preciso ter presente que a ideia da «sociedade do conhecimento» não é neutra e que aquilo de que falamos realmente é de uma sociedade de certos tipos de conhecimento que constantemente são valorizados em detrimento de outros, que são silenciados, numa hierarquia de saberes que vai relegando para lugares sombrios as ciências humanas e sociais, ao mesmo tempo que ilumina os conhecimentos potencialmente produtores imediatos de riqueza na economia de mercado.

As artimanhas imperialistas da razão científica ocidental fundemse com as da razão liberal num discurso ardiloso em torno das «sociedades do conhecimento», como se «desde há séculos a humanidade tivesse vivido nas sociedades da ignorância [...] [e, além disso,] sem que nunca seja sublinhada a importância dos conhecimentos endógenos» (Livro II, 2016: 121). Há, pois, que resistir em duas direcções, resistir à subordinação da investigação às agendas ocidentais, e resistir à subordinação da investigação única e exclusivamente aos imperativos do mercado.

Ela propõe uma epistemologia da transgressão, o que implica, do seu ponto de vista, «(re)considerar a identidade intelectual do investigador africano, bem como a sua capacidade para se libertar dos campos discursivos do Ocidente» (Livro II, 2016: 138). O que se espera é uma resposta original da ciência africana sobre como compreender África, o sujeito africano e o mundo de hoje. Colocam-se aqui questões fundamentais acerca dos quadros teóricos, das grelhas 
de leitura, mas também dos métodos. É necessário que surjam escolas de pensamento e não que se sigam escolas de pensamento, o que é lamentavelmente mais comum. O desafio de Ela é claro: da África devem surgir conhecimentos que os africanos precisam e que o mundo necessita. E, como isto, entramos no Livro III, A investigação africana face ao desafio da excelência científica.

Abraçar este desafio implica considerar que «a produção dos conhecimentos científicos opera-se num contexto agonístico» (Livro III, 2016: 21), que tem sido dominado pelo Ocidente. Os esforços de descentralização da produção e difusão do conhecimento (exercendo a ciência de um outro modo, como um diálogo de diferentes formas de racionalidade) constituem um enorme desafio, num contexto de profundas desigualdades entre o Norte e o Sul. O autor apresenta uma série de prerrogativas que considera essenciais para que os intelectuais africanos se lancem neste desafio. Mas, para além disso, chama a atenção para a necessidade de avaliar o ensino e os projectos das universidades africanas, analisando a sua relevância para as sociedades africanas e o necessário equilíbrio entre as ciências humanas e sociais, e as ciências físicas e naturais.

Além disso, «face à tradição do conhecimento fragmentado em elementos divididos e compartimentados nas disciplinas, reconhece-se a urgência de um trabalho científico capaz de atravessar as fronteiras entre disciplinas e de comunidade com outras ciências» (Livro III, 2016: 45). Neste caminho, os investigadores africanos, historicamente situados, social e culturalmente contextualizados, dialogam com o mundo ocidental da ciência, produzindo e disseminando conhecimento de África para o mundo. "Vemo-nos aqui confrontados com o desafio da internacionalização das instituições de formação e de investigação» (Livro III, 2016: 55), não necessariamente de acordo com aquilo que as agências internacionais esperam, mas de acordo com a sua própria agenda de descentralização da produção do conhecimento.

Afirmar-se nos sistemas mundializados do conhecimento requer a superação de limitações várias que o autor descreve com minucia na sua obra. Requer também novas parcerias com o Ocidente, de um tipo inteiramente novo, verdadeiramente baseadas em trocas e numa igual relação de forças. Neste particular, a par da sua epistemologia da transgressão, Ela propõe uma epistemologia dos lugares de produção de conhecimentos. Deste ponto de vista, «é necessário interrogar-se acerca da imagem da África 
ostentada pelo investigador que, no Norte, se envolve numa experiência de cooperação científica [...], (re)situando a cooperação científica no processo de descentralização dos lugares de produção dos conhecimentos» (Livro III, 2016: 98).

Para o autor, «é visível a necessidade, para o investigador africano, de definir o seu local» (Livro III, 2016: 105), redescobrindo as «ciências do Ocidente enquanto etnociências, tendo em conta o seu enraizamento e o seu significado culturais» (Idem). Este é o ponto de partida para pensar diferente. Eis o desafio.

\section{Referências bibliográficas}

ELA J.-M.

2014, Cheikh Anta Diop ou a honra de pensar. Luanda, Edições Mulemba; Ramada, Edições Pedago [«Reler África»].

Guba E. e Lincoln Y.

1994 (1. ${ }^{\text {a }}$ edição), «Competing paradigms in qualitative research», in Norman Denzin e Yvonna Lincoln (eds.), Handbook of qualitative research. Thousand Oaks, Sage Publications, pp. 105-117.

Mudimbe V. Y.

2013, A invenção de África. Gnose, filosofia e a ordem do conhecimento. Luanda, Edições Mulemba; Ramada, Edições Pedago [«Reler África»].

\section{Pedro Patacho}

(cf. supra, pp. 98-99) 